\title{
Memórias e experiências na Fábrica Rheingantz: políticas assistencialistas e a reprodução do operariado (Rio Grande/RS, 1920 a 1968)
}

\author{
Memories and experiences at the Rheingantz Factory: social \\ security policies and the reproduction of the working class (Rio \\ Grande/RS, 1920 to 1968)
}

\section{Caroline Duarte Matoso*}

Resumo: O artigo tem como objetivo analisar as políticas assistencialistas destinadas aos trabalhadores da Fábrica Rheingantz, tendo como enfoque as relações de gênero. Localizada no sul do Rio Grande do Sul, a Fábrica Rheingantz foi a primeira empresa têxtil do estado, sendo sua fundação datada de 1873. Investiga-se que além das trabalhadoras serem a principal mão de obra da indústria, estas eram também responsáveis pela reprodução do operariado. Explora-se as políticas assistencialistas que incentivavam as mulheres a constituírem família, através da documentação do setor administrativo da empresa e da metodologia de História Oral. O problema da pesquisa se fundamenta na análise de como o incentivo à constituição de um núcleo familiar (e suas implicações, trabalho de cuidado e reprodutivo) estiveram presentes no cotidiano fabril a partir das políticas de assistência social destinada ao operariado, estruturando as desigualdades de gênero na Fábrica Rheingantz. Para isso, o recorte temporal compreende diferentes momentos conjunturais brasileiro e local, de 1920 até 1968, ano em que a empresa encerrou as suas atividades.

Palavras-chave: Fábrica Rheingantz; políticas assistenciais; trabalho reprodutivo.

Abstract: The article aims to analyze the gender relations present in the care policies aimed at workers at the Rheingantz Factory. Located in the south of the state of Rio Grande do Sul,

* Doutoranda em História pela Universidade Federal do Rio Grande do Sul (UFRGS). Bolsista da Coordenação de Aperfeiçoamento de Pessoal de Nível Superior (CAPES). Mestre e graduada em História pela Universidade Federal de Pelotas (UFPEL). E-mail: historiamatoso@gmail.com. ORCID: https://orcid. org/0000-0003-0714-2928. 
with its foundation in 1873 , the Rheingantz factory was the first textile company in the state. It is investigated that working women, in addition to being the main labor force in industry, were also responsible for the reproduction of the working class. Through the documentation of the administrative sector of the factory and the methodology of Oral History, the care policies that encouraged women to start a family were explored. The research problem is related to how the incentive to establish a family nucleus (with implications for care and reproductive work) was present in the daily life of the factory from social assistance policies aimed at working women, structuring gender inequalities in the Rheingantz Factory. For this, the time frame comprises different moments of the national and local conjuncture, from 1920 to 1968 , the year in which the company ended its activities.

Keywords: Rheingantz Factory; care policies; reproductive work.

\section{Industrialização, Fábrica Rheingantz e as trabalhadoras}

A INDUSTRIalizaçÃo do Rio Grande do Sul iniciou-se com o estabelecimento da Fábrica Rheingantz no município de Rio Grande (RS) em 1872. Conforme Loner, ${ }^{1}$ se formaram dois polos industriais no estado, que não possuíam relação entre si: Pelotas-Rio Grande e Porto Alegre. A criação de polos distintos ocorreu pelas particularidades na formação socio-histórico-cultural do estado.

Em fins do século XIX, o governo cedeu pequenos lotes de terras no norte do estado a imigrantes alemães, visando ocupar a região fronteiriça e, assim, evitando a concorrência da metrópole espanhola com a portuguesa. Nessa região o crescimento econômico esteve baseado na pequena propriedade rural e na comercialização da agricultura e artesanato. Distintamente, na região sul do estado, se consolidaram unidades produtivas baseadas no latifúndio, monocultura e na mão de obra escravizada. ${ }^{2}$ No final do século XVIII, houve o crescimento da indústria do charque, no qual o município de Pelotas (RS) se sobressaiu na produção dessa mercadoria. Rio Grande (RS), ao possuir o único porto marítimo do estado, era responsável por exportar o charque produzido no município vizinho, ascendendo economicamente.

O enriquecimento dos charqueadores deu base à industrialização da região sul na segunda metade do século XIX. De acordo com Loner, ${ }^{3}$ as indústrias localizadas nos municípios de Pelotas (RS) e Rio Grande (RS) eram de grande porte, considerável capital financeiro nacional e internacional e pouca diversidade de mercadorias produzidas. No polo Porto Alegre (RS) se instalaram empresas de menor porte e maior diversidade produtiva.

1 LONER, Beatriz Ana. Construção de classe: operários de Pelotas e Rio Grande (1888-1930). Pelotas: Editora e Gráfica Universitária - UFPel, 2001.

2 IEPSEN, Eduardo. Jacob Rheingantz e a colônia de São Lourenço: da desconstrução de um mito à reconstrução de uma história. Dissertação (Mestrado em História) - Instituto de Ciências Humanas, Universidade do Vale do Rio dos Sinos, São Leopoldo, 2008.

3 LONER, op. cit. 
Acompanhando esse movimento, a Fábrica Rheingantz era uma empresa de grande porte e considerável capital financeiro investido. Em 1879 a indústria contava com um quadro de 900 funcionárias(os) e 100 costureiras que trabalhavam em suas residências. ${ }^{4}$ Fundada pelos empresários Carlo Guilherme Rheingantz, Miguel Tito de Sá e Herman Vater, a empresa era altamente qualificada em sua tecnologia. O estabelecimento Rheingantz importava da Europa o seu maquinário, e o seu desenvolvimento se refletia no crescente número de operários, nas altas taxas de lucro e na promoção de políticas assistencialistas voltadas para o seu operariado. ${ }^{5}$

Logo após a fundação da empresa, a sociedade com Tito de Sá e Hermann Vater foi desfeita, passando o proprietário Carlo Guilherme Rheingantz a deter o controle acionário. Conforme Paulitsch, ${ }^{6}$ em 1891 a fábrica se transformou em sociedade anônima, intitulada de União Fabril e Pastoril, contabilizando seu capital em torno de 3.500 contos de réis. Em suas primeiras décadas de funcionamento, a Fábrica Rheingantz passa por um processo de ascensão e, em 1907, encontrava-se entre as 100 maiores indústrias do país, possuindo capital de 5.000 contos de réis, 1.008 trabalhadoras(es) e valor da produção em 1.710 contos de réis. ${ }^{7}$

Diante da insuficiência do sistema de transporte do município, em 1884, foi construída a vila operária Rheingantz, que intensificou a aproximação entre o cotidiano de suas(seus) trabalhadoras(es) com as suas vidas laborais, em uma relação de simbiose entre o lar e o trabalho. Conforme Ferreira, ${ }^{8}$ a criação da vila operária e a sua arquitetura habitacional tornaram mais visíveis as hierarquias existentes entre as(os) trabalhadoras(es), assim como ampliou os dispositivos de dominação de classe.

Através da Sociedade de Mutualidade e Fundo de Auxílios Carlos G. Rheingantz, a Fábrica Rheingantz oferecia para seus funcionários uma série de políticas assistencialistas, a exemplo do que fariam outros "bastiões do paternalismo empresarial" do Rio Grande do Sul como a Renner e a Varig na década de $1940 .{ }^{9}$ Estas políticas eram: auxílio médico e pecuniário, serviço de obstetrícia, ajuda financeira em casos de gravidez, amparo aos filhos menores em caso de perda do pai, acidentes de trabalho, casamento da operária (desde que fossem consentidas formalmente pelos pais) e ajuda financeira para puérpera. Além disso, foram construídas creche e escolas para filhos(as) das(os) funcionárias(os).

4 Ibidem.

5 BRITTO, Natalia Soares de Sá. Industrialização e desindustrialização do espaço urbano na cidade de Pelotas (RS). Dissertação (Mestrado em História) - Instituto de Ciências Humana e da Informação, Universidade Federal de Rio Grande, Rio Grande, 2011.

6 PAULITSCH, Vivian da Silva. Rheingantz, uma vila operária em Rio Grande - RS. Dissertação (Mestrado em História) - Instituto de Filosofia e Ciências Humanas, Universidade Estadual de Campinas, Campinas, 2003.

7 BRITTO, op. cit.

8 FERREIRA, M. L. M. Os fios da memória: a Fábrica Rheingantz, entre o passado, presente e patrimônio. Horizontes Antropológicos, Porto Alegre, ano 19, n. 39, p. 69-98, jan./jun. 2013.

9 FORTES, Alexandre. Nós do quarto distrito: a classe operária porto-alegrense e a Era Vargas. Tese (Doutorado em História) - Instituto de Filosofia e Ciências Humanas, Universidade Estadual de Campinas, Campinas, 2001. 
Percebe-se que uma considerável quantidade das políticas desenvolvidas pelos empresários da Fábrica Rheingantz era voltada para a reprodução do seu operariado. A promoção do auxílio financeiro por casamento visava à formação de um núcleo familiar. Algo semelhante ao estudado por Ferreira sobre a indústria têxtil de Blumenau. Como comenta a autora, a ideia de trabalhador(a) era aquele(a) que possuía família:

As famílias consideradas ideais para trabalhar nas indústrias têxteis eram constituídas de um pai operário especializado e uma mãe dona de casa, também responsável por atividades ligadas às funções semiespecializadas na fábrica. ${ }^{10}$

Nesse sentido, o presente artigo procura fazer uma discussão sobre trabalho reprodutivo e trabalho fabril, à luz das políticas de assistência social criadas pelos empresários da Fábrica Rheingantz. Concordando com Bruschini, ${ }^{11}$ entende-se como importante ao campo dos estudos de gênero o entendimento da articulação entre o trabalho e a família para compreendermos as experiências femininas nos mundos do trabalho. O ambiente privado ocupa um lugar de privilégio nas discussões sobre a história das mulheres, visto que esse é um dos espaços em que as desigualdades de gênero se manifestam. Como Biroli ${ }^{12}$ aponta, a família e a maternidade são marcadas historicamente pela divisão sexual do trabalho, sobrecarregando as mulheres e restringindo a sua atuação na esfera pública.

Em consonância com Kergoat, ${ }^{13}$ entendo que se faz necessário irmos além das análises que abordam o trabalho reprodutivo como apenas um apêndice do trabalho no mercado formal, um dificultador da entrada das mulheres no mundo público: dupla jornada, acumulação e conciliação de tarefas. Pesquisas têm apontado para a articulação entre trabalho reprodutivo e trabalho produtivo, demonstrando uma relação de dependência. Pois, de acordo com Biroli, ${ }^{14}$ é o trabalho invisível e não remunerado que as mulheres exercem na esfera privada que possibilita a liberação da mão de obra masculina para o mercado de trabalho formal.

A partir da metodologia da História Oral exploro as memórias acerca das políticas de assistência social criadas pelos empresários da Fábrica Rheingantz entre os anos de 1920 a 1968, ano de encerramento das atividades da empresa. Almejando contribuir para os estudos dos mundos do trabalho e dos estudos de gênero, investigo como essas políticas de assistência social visavam à reprodução do operariado, produzindo relações de gênero, conformando trajetórias. Pois, como comenta Biroli, ${ }^{15}$ a produção social de gênero ocorre por meio de prescrições e julgamentos que conformam habilidades e preferências.

10 FERREIRA, Cristiane. Nas tramas do cotidiano: experiências de jovens e mulheres trabalhadoras na indústria têxtil de Blumenau (1958-1968). Estudos Históricos, v. 29, n. 59, p. 735, 2016.

11 BRUSCHINI, Cristina. Trabalho feminino: trajetória de um tema, perspectivas para o futuro. Estudos Feministas, n. 1, p. 17-31, 1994.

12 BIROLI, Flávia. Gênero e desigualdades: limites da democracia no Brasil. São Paulo: Boitempo, 2018.

13 KERGOAT, Daniéle. Divisão sexual do trabalho e relações sociais do sexo. In: HIRATA, Helena et al. (org.). Dicionário crítico do feminismo. Editora Unesp: São Paulo, 2009. p. 67-75.

14 Op. cit.

15 Op. cit. 
A metodologia que compõe esta pesquisa é a História Oral. A partir dela procurarei explanar sobre as experiências no mundo fabril, tendo como enfoque a subjetividade e significados narrados pelas(os) trabalhadoras(es) da fábrica Rheingantz sobre o passado vivido. Entende-se na presente pesquisa que a memória é: "uma reconstrução continuamente atualizada do passado". ${ }^{16}$ Conforme Alberti, ${ }^{17}$ a peculiaridade da história oral é que ela privilegia a recuperação do vivido conforme concebido por aquelas(es) que a viveram. Além disso, visto que o gênero feminino esteve por muito tempo ausente dos setores públicos, há pouca documentação escrita por mulheres, sendo as entrevistas orais uma fonte que nos possibilita compreender como as mulheres representam a si próprias e o mundo do trabalho. ${ }^{18}$

As entrevistas selecionadas para fins desta pesquisa integram um acervo constituído a partir de um projeto coordenado pela professora Maria Regina da Silva Freitas e alunas(os) do curso de História da Universidade Federal de Rio Grande (FURG), realizado durante as décadas de 1980 e 1990, com a finalidade de preservar a história da Fábrica Rheingantz e das(os) habitantes da cidade. O acervo possui 19 entrevistas realizadas com trabalhadoras(es), sindicalistas e empresários da Fábrica Rheingantz, possibilitando a produção de pesquisas sobre o mundo do trabalho do município de Rio Grande. Para este trabalho, realizei a leitura das 19 entrevistas e selecionei as que possuíam maiores marcadores de gênero nas narrativas.

Para uma análise mais aprofundada, explorei, também, a documentação do setor administrativo da Fábrica Rheingantz. Em 2013, sob intervenção do Ministério Público, a FURG ganhou a custódia do acervo do setor administrativo da Fábrica Rheingantz. Nos anos em que realizei as coletas das fontes, 2018 e 2019, a documentação ainda estava em processo de higienização e catalogação, não sendo disponibilizado para a pesquisa a totalidade do acervo. Acredito que esse acervo possibilitará novas pesquisas sobre a história do município e de suas(seus) trabalhadoras(es). As entrevistas e o acervo da Fábrica Rheingantz se encontram salvaguardados no Centro de Documentação Histórica Professor Hugo Alberto Pereira Neves, Fundação Universidade do Rio Grande.

\section{As operárias: divisão sexual do trabalho na Fábrica Rheingantz}

CONFORME BIROLI, ${ }^{19}$ falar em divisão sexual do trabalho é falar no que vem historicamente sendo definido como trabalho de mulher, competência feminina. A autora vai além e acrescenta: "Muitas das percepções sobre quem somos no mundo, o que representamos para as pessoas próximas e o nosso papel na sociedade estão relacionadas à divisão sexual do trabalho". ${ }^{20}$

16 CANDAU, Joël. Memória e identidade. Tradução: Maria Leticia Ferreira. São Paulo: Contexto, 2011. p. 9.

17 ALBERTI, Verena. História oral: a experiência do CPDOC. Rio de Janeiro: Editora Fundação Getúlio Vargas, 1990.

18 RAGO, Margareth. Trabalho feminino e sexualidade. In: DEL PRIORY, Mary (org.). História das mulheres no Brasil. São Paulo: Contexto, 1997.

19 Op. cit.

20 BIROLI, op. cit., p. 21 
Diante dessas premissas, entende-se que a separação das atividades desempenhadas por homens e mulheres na sociedade possuem dimensões materiais e simbólicas, construindo a identidade dos sujeitos históricos.

De acordo com Kergoat, ${ }^{21}$ há dois princípios que organizam a divisão sexual do trabalho: a separação e a hierarquização. Na sociedade moderna vimos emergir a domesticação feminina, na qual a esfera privada foi vista enquanto pertencente ao sujeito feminino. Em contrapartida, a esfera pública era entendida como um local de poder e de agência masculina. Esse movimento foi descrito pelas pesquisadoras de gênero como "domesticação feminina". A separação das atividades desempenhadas por homens e mulheres na sociedade foi acompanhada por uma hierarquização. As tarefas desempenhadas no ambiente doméstico: trabalho de cuidado e reprodutivo obtiveram menor prestígio na sociedade, em comparação com as atividades desempenhadas pelos homens no mundo público.

Davis $^{22}$ corrobora para o entendimento da divisão sexual do trabalho ao ressaltar que mesmo diante de discursos que relegavam as mulheres à esfera privada, poucas eram as que puderam se dedicar exclusivamente ao lar. As mulheres negras e brancas empobrecidas tiveram que se inserir no mercado de trabalho para poder sustentar a si mesmas e suas famílias. Conforme a autora, a domesticação influiu, também, na vida das trabalhadoras, que eram julgadas negativamente por estarem ocupando um lugar que não era delas: o espaço público.

No Brasil, Rago ${ }^{23}$ aponta que as mulheres e crianças formaram a principal mão de obra nas fábricas durante a Primeira República. A autora comenta sobre as dificuldades encontradas pelas mulheres em permanecer no mercado de trabalho:

Da variação salarial à intimidação salarial, da desqualificação intelectual ao assédio sexual, elas tiveram sempre de lutar contra inúmeros obstáculos para ingressar em um campo definido - pelos homens - como "naturalmente masculino". ${ }^{24}$

No município estudado, Rio Grande (RS), o número de operárias era expressivo, somando 2.223 trabalhadoras dos 4.325 trabalhadores fabris existentes em $1920 .{ }^{25}$ Havia uma divisão sexual do trabalho por ramos produtivos. Conforme Loner, ${ }^{26}$ as empresas de tecelagens, alimentícias e vestuário foram as que mais empregaram o sujeito feminino na cidade. Davis $^{27}$ corrobora para que entendamos essa constatação. De acordo com a autora, o tecer, costurar e produzir alimentos já eram atividades desempenhadas pelas mulheres no período pré-industrial. Com a industrialização, as mulheres passaram a desenvolver essas atividades nas fábricas, mudando suas relações e ritmos de trabalho.

21 Op. cit.

22 DAVIS, Angela. Mulheres, raça e classe. São Paulo: Boitempo, 2016.

23 Op. cit.

24 RAGO, op. cit., p. 582.

25 LONER, op. cit.

26 Op. cit.

27 Op. cit. 
Na Fábrica Rheingantz, as mulheres compunham a principal mão de obra da empresa durante todo o seu período de funcionamento. No interior da indústria havia uma separação de cargos ocupados a partir do gênero do(a) trabalhador(a). As lãs chegavam das estâncias de regiões próximas de Rio Grande em estado bruto, passando por diferentes etapas até chegar na fiação e na tecelagem. Essas etapas eram: lavagem da lã, escovação e tinturaria. A execução dessas atividades era semelhante ao trabalho rural, sendo pouco mecanizadas. De acordo com os cadernos do setor administrativo da empresa referentes a década de 1920, ${ }^{28}$ essas tarefas eram desenvolvidas apenas por trabalhadores homens.

As atividades mecanizadas, que requeriam menos força muscular - mas não menos degradante -, eram desempenhadas pelas mulheres e crianças: fiação e tecelagem. Esse trabalho necessitava atenção e cuidado, características vistas historicamente enquanto femininas.

Entende-se que a segregação de gênero nas atividades descritas acima está relacionada com a construção da masculinidade operária da época. Conforme Matos, ${ }^{29}$ o período de urbanização e industrialização iniciado no Brasil, em meados do século XIX, buscou formular dispositivos de controle social com a finalidade de incumbir um novo perfil nas camadas populares. Ao analisar discursos de médicos, higienistas e eugenistas do início do século XX

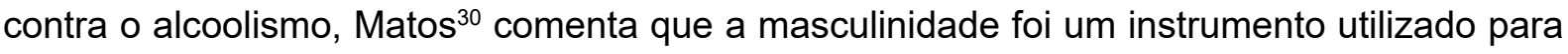
controlar os homens das classes populares. Essa masculinidade estaria associada aos atos de possuir, tomar, dominar e se afirmar, de ser o provedor da família, o bom pai e marido dedicado, forte e ordeiro na rotina do trabalho.

Bilhão, ${ }^{31}$ ao analisar os operários do município de Porto Alegre (RS) do início do século $X X$, comenta que a construção da identidade masculina operária estava ligada à ideia de valentia, na qual os homens da classe operária reafirmavam a sua masculinidade através de ações violentas. Como continua a autora:

Isso não significa, obviamente, que a violência seja por si só e isoladamente um fator definidor dos papéis de gênero, mas sim que ela pode ser uma "via de acesso" à compreensão da construção da identidade masculina relacionada à identidade operária, especialmente porque estou falando de uma sociedade que, em muitos momentos, associava a imagem do masculino à valentia e legitimava o uso da violência, caso necessário reafirmar ou salvaguardar a honorabilidade pessoal ou coletiva. ${ }^{32}$

Nas narrativas dos operários e empresários da Fábrica Rheingantz, analisa-se a existência de um modelo de masculinidade idealizado, nas justificativas acerca da divisão sexual do trabalho.

28 Acervo Fábrica Rheingantz. Centro de Documentação Histórica Professor Hugo Alberto Pereira Neves, Fundação Universidade do Rio Grande, Rio Grande.

29 Op. cit.

30 Op. cit.

31 BILHÃO, Isabel Aparecida. Identidade e trabalho: análise da construção dos operários porto-alegrenses (1896 a 1920). 280 f. Tese (Doutorado em História) - Instituto de Filosofia e Ciências Humanas, Universidade Federal do Rio Grande do Sul, Porto Alegre, 2005.

32 Op. cit., p. 132. 
O trabalho pesado, braçal ou que (para os entrevistados) possuíam maior "responsabilidade" eram vistos enquanto tarefas que deviam ser desempenhadas pelos homens.

O operário Dario Camposilvan ${ }^{33}$ saiu da Itália em 1949 para desembarcar em terras brasileiras. Possuindo formação técnica e experiência na área têxtil, no mesmo ano de sua chegada em Rio Grande (RS) inicia seu ofício como contramestre de seção na Fábrica Rheingantz. Em sua entrevista realizada em 1983, o entrevistado comenta sobre a divisão sexual do trabalho no interior da empresa. Conforme Dario Camposilvan, a maioria das tecelãs eram mulheres. Em contrapartida, os cargos de maior prestígio social como mestre e contramestre de seção eram destinados ao sexo masculino. Ao ser perguntado se havia mais mulheres do que homens na tecelagem, Dario Camposilvan comenta:

Quem trabalhava nas máquinas eram só mulheres. Os homens eram para a manutenção da máquina, entendeu? Só o contramestre tinha 22 máquinas com responsabilidade. Responsabilidade. Mas quem trabalhava nas máquinas eram as mulheres. (...) Nesse ramo a mulher tem mais agilidade, não é? Que o homem...34

O número superior de trabalhadoras na sessão da tecelagem aparece justificada com uma agilidade que seria inerente ao sexo feminino. A máquina e a trabalhadora aparecem nas narrativas como uma unidade, quase como sinônimos. Algo que podemos perceber também nas narrativas das operárias Soeli Botelho e Margarida Soares Reis, tecelãs da Fábrica Rheingantz.

Soeli Botelho, que começou a trabalhar na Fábrica Rheingantz aos 14 anos de idade, em 1947, comenta que a empresa trabalhava 24 horas por dia. Após o Decreto do Trabalho Feminino . $^{\circ}$ 21. 417, de 17 de maio 1932, as mulheres foram proibidas de trabalhar à noite, entre as 22 horas e 5 horas. Para a operária Soeli Botelho, em consequência ao decreto, os homens passaram a trabalhar "nas nossas máquinas". ${ }^{35}$

A naturalização das atividades desempenhadas por homens e mulheres no interior da Fábrica Rheingantz aparecem com maior ênfase nas entrevistas realizadas com os operários. O contador do setor administrativo Pedro Carlos Peixoto Júnior, que começou a trabalhar na empresa em 1928, também comenta sobre o período de proibição do trabalho feminino noturno. Pedro Carlos Peixoto Júnior comenta que após o Decreto do Trabalho Feminino, os empresários da Rheingantz passaram a recrutar trabalhadores pernambucanos para trabalhar na tecelagem, pois, segundo o entrevistado, “(...) aqui no sul, o conceito de tecelagem é para mulher, inclusive". ${ }^{36} \mathrm{O}$ trabalho na tecelagem, nas máquinas, aparece como um definidor de gênero. Um ofício que não só era visto como feminino, como incompatível aos homens gaúchos.

33 CAMPOLSILVAN, Dario. Depoimento concedido em 1981. Rio Grande: Acervo Fábrica Rheingantz, Centro de Documentação Histórica Professor Hugo Alberto Pereira Neves, Fundação Universidade do Rio Grande.

34 CAMPOSILVAN, op. cit., p. 9.

35 BOTELHO, Soeli. Depoimento concedido em 1981. Rio Grande: Acervo Fábrica Rheingantz, Centro de Documentação Histórica Professor Hugo Alberto Pereira Neves, Fundação Universidade de Rio Grande, p. 7.

36 PEIXOTO, Pedro Carlos Jr. Depoimento concedido em 1984. Rio Grande: Acervo Fábrica Rheingantz, Centro de Documentação Histórica Professor Hugo Alberto Pereira Neves, Fundação Universidade do Rio Grande, p. 3. 
O desenhista técnico Áureo Nunes de Almeida começou a trabalhar na Fábrica Rheingantz no ano de 1943, seguindo a trajetória do seu pai, dos seus irmãos e das suas irmãs. Em sua entrevista, a divisão sexual do trabalho aparece na sua fala, diante de justificativas biológicas. Como podemos averiguar na seguinte fala:

É que na minha seção os homens eram empregados nos teares mecânicos? Então aí eram empregados homens porque era um serviço mais pesado que a tecelagem de tecidos. Ele fazia esses, esses tapetes bucles e de veludo. Passadeira. E o tapete feito à mão era um trabalho muito especial; a mulher mesmo é que eu acho que é mais, mais adaptada para esse tipo de serviço. É muito minucioso, é muito cansativo e o homem não tem essa capacidade de, de absorção do trabalho como tem a mulher. Fazer sempre a mesma coisa, de modo repetitivo, acredito que a mulher tem mais... é muito mais bem armada para isso. ${ }^{37}$

Os apontamentos teóricos de Souza-Lobo ${ }^{38}$ corroboram para o entendimento das narrativas descritas acima. Conforme a autora, a exploração da mão de obra feminina funda-se nas relações sociais e nas representações culturais. Souza-Lobo comenta que as profissões vistas como "femininas", na realidade, são uma extensão das funções e representações das mulheres no trabalho reprodutivo. Como segue a pesquisadora acerca do trabalho feminino no mercado de trabalho: "Assim, os dedos ágeis, a paciência, a resistência à monotonia são consideradas próprias da mão de obra feminina". Fala-se em extensão do trabalho reprodutivo, pois as habilidades descritas acima são essenciais para as atividades domésticas e de cuidado. Ao justificar a distinção entre trabalhos considerados femininos e trabalhos considerados masculinos a partir de discursos naturalistas, desconsidera-se o treinamento formal que os sujeitos recebem ao longo de suas vidas.

Percebe-se que a máquina era parte da identidade das operárias enquanto trabalhadoras. E este foi um sentimento que perdurou após o fechamento da empresa. De acordo com Ferreira, ${ }^{39}$ nos anos de 1997 e 1998, realizaram-se audiências públicas no município de Rio Grande (RS) para a patrimonização da Fábrica Rheingantz e da vila operária Rheingantz, em um processo turbulento de luta contra os interesses imobiliários. Os antigos trabalhadores da empresa se reuniam no interior da fábrica para articularem os seus interesses. Significativamente, os encontros aconteciam a partir de dois grupos diferentes: um de mulheres e outro de homens. Como Ferreira ${ }^{40}$ aponta, as mulheres se reuniam no setor de costura, enquanto os homens realizavam as suas reuniões na portaria da fábrica. Isso indica que a identidade e solidariedade entre as trabalhadoras persistiu mesmo após o fechamento da empresa. Ao se reunirem no setor da costura, entende-se que essa identidade estava relacionada com o local de trabalho no qual elas trabalharam, provavelmente, décadas de suas vidas.

37 PEIXOTO, op, cit., p. 8.

38 SOUZA-LOBO, Elisabeth. A classe operária tem dois sexos: trabalho dominação e resistência. São Paulo: Expressão Popular, 2021.

39 Op. cit.

40 Op. cit. 


\title{
Família operária Rheingantz e as políticas voltadas à reprodução do operariado
}

COMO APONTA BIROLI, ${ }^{41}$ a família toma forma em instituições, valores, normas e práticas cotidianas. Não sendo a-histórica, a família é fruto de processos sociais, da interação entre institucional, simbólico e material. A urbanização, a industrialização e o trabalho feminino fabril modificaram os arranjos familiares preestabelecidos, abrindo brechas para uma ruptura e uma crise na ordem constituída. De acordo com Rago, ${ }^{42}$ a família foi objeto de análise de humanistas, médicos e higienistas que buscavam redefinir o seu papel na sociedade nascente.

Matos, analisou discursos de médicos, higienistas e eugenistas sobre as classes populares, no qual modelos de masculinidade e feminilidade estavam presentes. Ao estudar um discurso médico do início do século XX, a autora comenta:

\begin{abstract}
O texto descreve um momento primeiro de harmonia, ordem e felicidade, sedimentado no homem provedor, trabalhador, operário dedicado, bom marido, pai carinhoso e atencioso, tendo como uma companheira uma mulher encantadora, carinhosa, boa mãe e esposa dedicada, criando um lar humilde, perfeitamente moralizado, cristão e feliz, um verdadeiro "sacrário sublime", marcado pela amizade, pelo afeto e doce convívio. O lar era formado por essas pessoas cujos perfis apresentados eram claros nas apresentações idealizadas do feminino e do masculino. ${ }^{43}$
\end{abstract}

Aponta-se que a formação de uma família nuclear fechada em si, heteronormativa, monogâmica e patriarcal corroborou para o processo de controle social necessário às novas relações de trabalho que emergiram com a industrialização. Os discursos sobre a família nuclear conformaram relações idealizadas do que é ser homem e do que é ser mulher na sociedade. O homem era representado como o provedor da família, enquanto o ideal de mulher estava ligado ao cuidado, ao mundo doméstico, como bem apontado por Matos. ${ }^{44}$

O trabalho industrial requeria um novo modelo de trabalhador: rígido, disciplinado. Como aponta Thompson, ${ }^{45}$ o trabalho na indústria acarretou a reestruturação dos hábitos do trabalho: "novas disciplinas, novos estímulos, e uma nova natureza humana em que esses estímulos atuassem efetivamente". ${ }^{46} \mathrm{O}$ tempo se tornou algo primordial para a nova sociedade emergente, pois este passou a representar a moeda. O tempo do lazer, do ócio, deveria ser reduzido ao máximo. Como aponta Thompson:

Aqueles que são contratados experienciam uma distinção entre o tempo do empregador e o seu próprio tempo. E o empregador deve usar o tempo de

\footnotetext{
41 Op. cit.

42 Op. cit.

43 Op. cit., p. 64.

44 Op. cit.

45 Op. cit.

46 Op. cit., p. 269.
} 
sua mão de obra e cuidar para que não seja desperdiçado: o que predomina não é a tarefa, mas o valor do tempo quando reduzido a dinheiro. O tempo agora é moeda: ninguém passa o tempo, e sim o gasta. ${ }^{47}$

Na Fábrica Rheingantz, a construção da vila operária serviu como um instrumento disciplinador, pois aproximou a vida cotidiana do trabalhador ao trabalho. A partir das entrevistas, explora-se que havia um modelo de família desejado pelos empresários Rheingantz, que buscavam incentivar a sua formação por meio de políticas de assistência ao operariado.

A operária Soeli Botelho comenta sobre as dificuldades em acessar a política de concessão de moradias na vila operária, pois era dada prioridade para os "chefes de família":

Trabalhei tantos anos lá, sempre pedia... Sempre pedia, porque primeiro eles não davam para as mulheres. (...) Não, só para homens. (...) No tempo dos Rheingantz, é. Não dava casa para a mulher, só para homens. Para chefe de família, né. A única mulher que tinha era a Marina, que era caixa geral. ${ }^{48}$

Na memória de Soeli Botelho, o fato de ela ser mulher foi um impeditivo para acessar a política de concessão a moradias. Ao comentar que os empresários Rheingantz davam moradia apenas para os "chefes de família", percebe-se que o modelo de homem provedor fez parte do cotidiano fabril Rheingantz. Nessa concepção, o chefe de família é aquele que detém o poder decisão, uma figura de autoridade, algo semelhante aos discursos dos médicos higienistas analisados por Matos. ${ }^{49}$ Representa, também, que na memória de Soeli Botelho, os operários tinham mais vantagens que as operárias, mesmo que estas fossem maioria na mão de obra.

A operária Margarida Soares também comenta sobre a política de concessão de moradias da empresa. Começando a trabalhar na Fábrica Rheingantz em 1922, quando tinha nove anos de idade, permanecendo na empresa durante 40 anos de sua vida, relata as dificuldades ao acesso de uma moradia na vila operária. Não conseguindo acesso às residências, Margarida comenta que "Não, não eram escolhidos. Dependia da sorte". 50 Significativamente, o contramestre Dario Camposilvan fala sobre as facilidades de conseguir morar na vila operária:

Eu fui convidado para trabalhar na turma da noite, que na época tinha muito serviço [...] e aí eu fui convidado para assumir a responsabilidade da turma da noite. Aí eu disse que não podia assumir, porque onde eu morava tinha muito barulho e não podia dormir de dia. O gerente no mesmo... no mesmo dia, na mesma hora me deu uma chave da casa, no subúrbio, perto do campo São Paulo lá, onde que não faz... não tinha movimento, pouco movimento naquela época. E foi quando que me deram a casa em 1956. Faz 26 anos que eu moro lá. ${ }^{51}$

47 Op. cit., 272.

48 Op. cit., p. $31 / 32$.

49 Op. cit.

50 ROCHA, Margarida Reis. Depoimento concedido em 1987. Rio Grande: Acervo Fábrica Rheingantz, Centro de Documentação Histórica Professor Hugo Alberto Pereira Neves, Fundação Universidade do Rio Grande, Rio Grande, p. 3.

51 Op. cit., p. 20 
A preferência ao cedimento de casas de moradia aos "chefes de família" aparece, também, na fala do contador Pedro Carlos Peixoto Júnior:

Bom, existia (seleção prévia do beneficiado). Existia o chefe de família como base, não é? E se a esposa também trabalhasse aqui, porque eram dois beneficiados que iriam morar perto da fábrica. $E$ quanto ao aluguel era simbólico. Era um cruzeiro, naquela época. Naquela época mesmo $2 \$ 000$ réis. Era um cruzeiro, dois cruzeiros... Era simbólico. Simplesmente simbólico. E essas casas ainda existem. Elas foram adquiridas pela companhia Inca e os operários ainda residem. ${ }^{52}$

As narrativas descritas acima entram em consonância com os apontamentos teóricos de Biroli. ${ }^{53}$ De acordo com a autora, a idealização da família ocorre por uma perspectiva patriarcal e heteronormativa, criando vantagens aos homens. O modelo de arranjo familiar idealizado controla os corpos e normatiza os afetos, criando restrições aos indivíduos.

É importante ressaltar que os modelos de feminilidade e masculinidade embasaram os papéis a serem desempenhados pelos sujeitos que compõem a família nuclear. Entende-se enquanto feminilidade, discursos construídos por uma visão masculina, na qual espera-se que a mulher corresponda. ${ }^{54}$ Nesse modelo de feminilidade construída na modernidade, a maternidade e o lar eram apresentados como o destino natural de todas as mulheres.

O sentimento de nostalgia ao passado vivido na Fábrica Rheingantz, presente nas narrativas das(os) entrevistadas(os), entra em dissonância quando as operárias narram as políticas de promoção de residências na vila operária. Percebe-se que o modelo de chefe de família como um dos definidores para o recebimento de residências fomentou memórias conflitantes acerca da suposta benfeitoria dos empresários Rheingantz. As entrevistas de Soeli Botelho e Margarida Soares apresentam ressentimento sobre a forma na qual se desenvolvia a seleção das moradias, demonstrando as limitações da dominação e do consenso social na promoção de políticas assistencialistas dos empresários Rheingantz.

Como Thompson comenta, paternalismo requer calor humano, em uma relação mutuamente concedida. As(os) operárias(os) tinham conhecimento das relações sociais em que estavam inseridos, compreendendo a política de moradias na vila operária Rheingantz como um direito adquirido por serem trabalhadoras(es) da empresa. Ao possuir o critério de seleção para a contemplação das residências, o modelo de chefe de família, essa política assistencialista foi entendida pelas operárias enquanto uma injustiça.

Como já mencionado, os empresários da Fábrica Rheingantz promoveram uma série de políticas de assistência social para os operários. As operárias da empresa recebiam enxoval ao se casarem e auxílio financeiro por filho nascido. Havia parteiras funcionárias da indústria Rheingantz que auxiliavam as trabalhadoras no período de gestação e durante o puerpério. Assim como a criação de creche e escola.

52 Op. cit., p. 5.

53 Op. cit.

54 KEHL, Maria Rita. Deslocamentos do feminino. Rio de Janeiro: Imago, 2008 
Como já mencionado, o trabalho feminino foi amplamente discutido por diferentes setores da sociedade. Como interroga Perrot: "As mulheres podem, devem ter acesso ao salário, isto é, receber uma remuneração individual, deixando a casa, o lar, que era o seu ponto de apoio e utilidade?". ${ }^{55} \mathrm{O}$ trabalho exercido pela mulher no ambiente privado sustentava o modelo econômico vigente, visto que era ele que proporcionava a reprodução do operariado. ${ }^{56} \mathrm{Com}$ a introdução das mulheres nas indústrias, crescia a preocupação com o cuidado e a formação das crianças e adolescentes.

De acordo com Bilhão, "pode-se perceber que a entrada das mulheres no mundo produtivo suscitou um amplo debate, via imprensa, sobre o novo papel da mulher e os riscos e consequências dele decorrentes para a sociedade e para as famílias". ${ }^{57}$ Como continua a autora, havia a preocupação de que a inserção da mulher nas fábricas pudesse dissolver os laços familiares, relegando crianças e adolescentes ao abandono.

A partir da literatura e das entrevistas analisadas neste trabalho, aponta-se que os empresários brasileiros lidaram de diferentes formas acerca do trabalho feminino. Rezende ${ }^{58}$ comenta que a empresa Amazonas, de Franca (SP), não contratava mulheres casadas por estas estarem mais propensas a engravidar. Segundo a empresa, as trabalhadoras que constituíam proles faltavam mais ao serviço para cuidarem de suas proles.

Aindústria Renner, de PortoAlegre, criou uma creche para os filhos das(dos) operárias(os), visando a uma maior fixação da mão de obra feminina na empresa. De acordo com Fontes, havia uma preocupação em tornar mais estável a mão de obra feminina, visto que muitas vezes as mulheres deixavam de trabalhar após o casamento. Outra política assistencialista concedida pela fábrica Renner era o auxílio financeiro concedido "para a esposa do operário" a cada filho nascido (a partir do terceiro). Essa política visava a aumentar a prole operária, garantindo assim a reprodução da mão de obra da empresa. Significativamente, para ser beneficiária desse auxílio exigia-se que a trabalhadora trabalhasse apenas em seu lar, cuidando de seus filhos e de seu esposo.

Silva, ${ }^{59}$ pesquisando a indústria de extração de carvão mineral da região de São Jerônimo (RS), entre os anos de 1883 e 1945, constatou que as numerosas taxas de mortalidade infantil se configuravam como um problema para os empresários do setor. Atribuindo a desnutrição como um dos fatores que levavam aos altos índices de mortalidade infantil, a empresa

55 PERROT, Michelle. Minha história das mulheres. São Paulo: Contexto, 2008. p. 109.

56 FEDERICH, Silvia. O patriarcado do salário: notas sobre Marx, gênero e feminismo. São Paulo: Boitempo, 2021.

57 BILHÃ̃, Isabel Aparecida. Mulheres operárias na Porto Alegre da virada do século XIX para o XX. In: IX ENCONTRO ESTADUAL DE HISTÓRIA DA ANPUH/RS - Vestígios do passado: a História e suas fontes, 2008, Porto Alegre/RS. ANAIS[...] [recurso eletrônico]. Porto Alegre: UFRGS, 2008. p. 1-12. Disponível em: http://eeh2008.anpuh-rs.org.br/resources/content/anais/1210989240_ARQUIVO_TextoCompleto-ANPUHRS. pdf. Acesso em: 20 abr. 2020. p. 2.

58 REZENDE, Vinicius Donizete de. Tempo, trabalho e conflito social no complexo coureiro-calçadista de Franca-SP (1950-1980). Tese (Doutoramento em História) - Instituto de Filosofia e Ciências Humanas, Universidade Estadual de Campinas, Campinas, 2012.

59 SILVA, Cristina Ennes da. Nas profundezas da terra: um estudo sobre a região carbonífera do Rio Grande do Sul (1883/1945). Tese (Doutorado em História) - Instituto de Filosofia e Ciências Humanas, Pontifícia Universidade Católica do Rio Grande do Sul, Porto Alegre, 2007. 
promoveu concursos de robusteza infantil, como um incentivo às mães amamentarem seus filhos. Podiam se inscrever mães de crianças de até 12 meses, concedendo aos ganhadores prêmios monetários.

A Fábrica Rheingantz buscou resolver o problema de reposição de sua mão de obra incentivando as trabalhadoras a se casarem e a constituírem família. Os filhos da família operária ingressavam para trabalhar na Fábrica Rheingantz desde a infância. A organização dos turnos da escola da empresa era realizada a partir de um revezamento: metade das crianças trabalhavam em um turno, enquanto a outra ia à escola, e vice-versa. Ao trabalharem desde as suas infâncias, os corpos operários eram moldados para exercerem a disciplina exigida pelos industriais. De acordo com o operário Áureo Nunes de Almeida:

Ah, e dentro do espírito da companhia, eles gostavam que os próprios empregados casassem entre si e formassem família e os filhos continuassem dentro da companhia. Isto era uma recomendação desde o tempo do comendador Rheingantz. E como o meu pai trabalhava lá já, tinha irmãos que trabalhavam lá. Eu estava no ginásio, no Lemor Jr., o $4^{\circ}$ ano do ginásio, e fui para a turma que terminou a $4^{\text {a }}$ série. Quando tiraram a $5^{\text {a }}$ série e eu precisava prover a minha, um pouco da minha subsistência. Afinal, eu ia estudando no científico, e então eles ofereceram vaga ao meu pai para mim como copiador de receitas na tinturaria. Trabalhando só meio turno, ou então trabalhava de manhã, das 7:15 às 11:15. De tarde eu ia para o ginásio e de noite eu fazia tiro de guerra. E assim, a minha atividade naquele ano foi essa. Por isso que também ajudou a arrebentar a hemoptise da minha "bronquetasia". Eu tenho ela, já é uma coisa de nascença. ${ }^{60}$

Conforme Ferreira, ${ }^{61}$ ao analisar uma empresa têxtil de Blumenau, o trabalho infantil foi fundamental para o funcionamento da engrenagem fabril. Mesmo diante das tensões e desigualdades internas da família operária, de acordo com a autora, havia um senso de unidade e metas coletivas, no qual (...) "A sobrevivência era o principal fator de motivação para tal procedimento, e os menores de idade não chegavam sequer a completar o ensino básico e já eram recrutados para ajudar no sustento familiar". ${ }^{62}$

Percebe-se, nas narrativas dos operários e operárias, que ao trabalharem desde a infância na Fábrica Rheingatz, criou-se um sentimento de afetividade entre o trabalhador e empresa, possivelmente mascarando os conflitos de classe. Soeli Botelho, ao lembrar de sua infância, sua adolescência, relaciona essa lembrança com a empresa, as seções que trabalhou, as brincadeiras com as crianças na vila operária:

Olha eu me criei na seção de tapete. Inclusive a senhora sabe que eu brincava muito, eu trabalhava muito. Era uma criança, não é? Um dia que eu ia para a casa sem levar um carão do alemão, parece que eu tinha deixado uma coisa lá dentro. Porque todos os dias ele me dava um carão. Porque eu brincava muito, eu trabalhava muito, eu procurava fazer o meu serviço muito direito, mas nas horas eu saía a brincar no tear. Enquanto as outras terminavam a carreira depois eu saía para brincar nos teares. Inclusive eu

\footnotetext{
60 ALMEIDA, Áureo Nunes. Depoimento concedido em 1987. Rio Grande: Acervo Fábrica Rheingantz, Centro de Documentação Histórica Professor Hugo Alberto Pereira Neves, Fundação Universidade do Rio Grande, p. 3.

61 Op. cit.

62 FERREIRA, op. cit., p. 730.
} 
colocava chapéu, colocava salto alto das moças que eram padroneiras lá que tinham sapato alto e eu ia brincar que eu era visita. Que eu estava visitando os tapetes e todos vinham me dar e gostava de largar os braços nos teares. Uma vez o tear me deu um "laçasso" de eu largar o braço, me jogou longe. Ele (supervisor) até me disse uma vez: eu não vou te ver trabalhando sem cabeça no tear. ${ }^{63}$

Soeli Botelho começou a trabalhar após o falecimento de seus pais, quando tinha 14 anos. Sua irmã mais velha a levou para a empresa e logo iniciou o seu ofício. A sua fala descrita acima nos faz refletir sobre o trabalho infantil. Para a entrevistada, o local de trabalho era também um local onde ela brincava, onde construiu laços com suas supervisoras e colegas. Soeli Botelho comenta que brincava, mas só depois de trabalhar "muito", algo que ela repete algumas vezes na mesma frase. Desde a sua infância, ao ser repreendida por seu supervisor, o "alemão com um carão", aprendeu que o lazer não era para ela. Aprendeu que seu corpo precisava ser disciplinado. As suas brincadeiras na seção do tapete são recordadas como um ato de subversão, que ela tenta justificar ao falar que só brincava após trabalhar muito.

Aos trabalhadores menores de idade, pagava-se a metade do salário destinado a um trabalhador adulto, que conforme Soeli Botelho: "Talvez fosse por economia deles, porque menor naquele tempo ganhava metade do salário". ${ }^{64} \mathrm{~A}$ partir do rebaixamento dos salários destinados aos meninos e às meninas, ampliava-se a exploração da mão de obra. Era um período de treinamento, um período de educar corpos e comportamentos.

As memórias das(os) entrevistadas(os) nos fazem refletir como os trabalhadores perceberam e redefiniram as políticas voltadas à reprodução do operariado. Aponta-se que a admissão com maior facilidade de filhas(os) de trabalhadoras(es) da empresa permitia para a família operária uma maior estabilidade, podendo ser entendida como uma estratégia de transmissão geracional de profissão. A trajetória da operária Soeli Botelho e do desenhista técnico Áureo Nunes de Almeida corroboram para algumas reflexões acerca da percepção dos trabalhadores acerca desse fenômeno.

Áureo Nunes de Almeida ingressou na empresa ainda criança e ocupou diferentes tarefas até se tornar desenhista técnico da Fábrica Rheingantz. Seu pai trabalhava na empresa há 52 anos, ocupando um cargo de destaque no setor administrativo. Áureo Nunes de Almeida narra que sua família tinha relações próximas com a família Rheingantz, sendo ele amigo de infância dos filhos dos acionistas. Comentando sobre o clima de "familiaridade" na vila operária, o entrevistado narra:

Eu fui muito ajudado, amparado em fases da minha vida. (...) O seu Paulo, como era chamado, ele me chamou no escritório e disse que eu queria, que eu precisava ser, ah... entrar no lugar do desenhista técnico, o Hermelino, não é? Depois que eu estava

63 BOTELHO, op. cit., p. 25.

64 Op. cit., p. 2. 
trabalhando com ele uns meses como office boy, tanto que eles imediatamente me tiraram da tinturaria (...) (ALMEIDA, p. 3).

Áureo Nunes de Almeida comenta que quando informou que não possuía experiência e formação como desenhista, o acionista respondeu que todos os irmãos de Áureo eram conhecidos como desenhistas e ele também deveria ser. Percebe-se que as relações sociais na vila operária Rheingantz e as hierarquias presentes entre os diferentes setores que compunham a empresa poderiam significar maiores vantagens na ocupação profissional dos sucessores das(os) trabalhadoras(es).

As hierarquias expressas no conjunto arquitetônico da vila operária eram também refletidas nas relações sociais entre os moradores. A estabilidade empregatícia que o recrutamento familiar possibilitou à família operária também foi acompanhada por uma continuidade geracional ocupacional e, consequentemente, de diferenciações nas oportunidades de ascensão de carreira.

Significativamente, as operárias entrevistadas permaneceram durante toda a sua trajetória laboral sendo tecelãs. Distintamente de Áureo Nunes de Almeida, Soeli Botelho narra que sua admissão foi realizada com facilidade, mas não menciona um "amparo" e "ajuda" em diferentes fases de sua vida. Conforme exposto por Soeli Botelho, seu contato com a família Rheingantz era apenas profissional, demonstrando certa distância e hierarquia na relação. Ao comentar sobre um episódio em que brincou com os filhos de um acionista da empresa, Soeli Botelho diz que a esposa do acionista era uma "santa" por tê-la deixado brincar com os seus filhos.

Entendo que o recrutamento familiar foi uma prática exercida pelos empresários Rheingantz como uma forma de repor sua mão de obra. Todavia, essa política assistencialista fez também parte de uma estratégia operária de transmissão de profissão e garantia de emprego. No período abordado, o emprego assalariado com carteira assinada ainda era limitado. No recenseamento do Ministério da Agricultura, Indústria e Comércio, realizado em 1920, aponta-se que no Rio Grande do Sul a maior parte da população se encontrava em profissões mal definidas ou sem profissão: enquanto os trabalhadores da indústria somavam 84.712, os trabalhadores descritos no setor "diversos" somavam 1.582.974. Vale destacar que os trabalhadores localizados no setor diverso são aqueles que possuem maior vulnerabilidade nas relações e vínculos empregatícios. Ser filho(a) de um(a) trabalhador(a) da Fábrica Rheingantz poderia significar maior facilidade em seguir a profissão de seus pais e conseguir um emprego na indústria.

\section{Políticas assistencialistas: práticas paternalistas}

COMO APONTA THOMPSON, ${ }^{65}$ a Revolução Industrial alterou a natureza e a intensidade do trabalho. Conforme o autor, uma proporção substancial da força de trabalho se tornou mais

65 Op. cit. 
livre da disciplina laboral diária, mais livre para escolher seus empregadores, diminuindo a posição de dependência vivida anteriormente. Em um processo de desmantelamento das antigas obrigações de mutualidade, o antagonismo social se tornou mais visível e intrínseco às novas relações de trabalho.

Se referindo à sociedade inglesa do século XVIII, Thompson ${ }^{66}$ comenta que esse foi um período de crise das práticas paternalistas, um período de transição. Como o próprio autor nos atenta, o termo paternalista é utilizado para análise de realidades díspares no tempo e espaço, sendo demasiado amplo. Assim como Rezende, ${ }^{67}$ para fins deste trabalho, o conceito de paternalismo será utilizado para a análise de relações de trabalho específicas. Apoiado nos pressupostos teóricos de Thompson, entende-se enquanto paternalismo "uma concentração de autoridade econômica e cultural". ${ }^{68}$

Todavia, a necessidade de estabilidade da força de trabalho e do sentimento de harmonia social demandou que novas formas de paternalismo fossem criadas. Thompson, discorrendo sobre a crise do paternalismo, comenta que continuaram "fortes os controles econômicos domésticos mais antigos, e é possível que tenhamos subestimado o alcance das áreas de "dependência" ou "clientela" da economia". ${ }^{69}$ Os donos do poder e do dinheiro continuavam a exercer controle sobre a vida e expectativas dos de baixo. Esse controle, conforme Thompson, ${ }^{70}$ era exercido primordialmente pela hegemonia cultural, colocando em segundo plano o controle econômico e militar.

Na Fábrica Rheingantz percebe-se que a criação de políticas sociais foi um instrumento utilizado pelos empresários para manter a coesão da mão de obra da empresa, em discursos que reivindicavam o sentimento de "família" entre trabalhadores e empresários da indústria. As entrevistas analisadas neste trabalho foram realizadas na década de 1980 e de 1990, período no qual a empresa havia encerrado suas atividades. Ao recordarem as suas trajetórias laborais na Fábrica Rheingantz, os entrevistados lembram com saudosismo o tempo passado.

Conforme Fortes, ${ }^{71}$ a Fábrica Rheingantz assumiu um papel de vanguarda na promoção de políticas sociais destinadas aos seus trabalhadores no Rio Grande do Sul. No ano de 1882, a empresa criou uma escola destinada aos filhos das(os) operárias(os), demonstrando o seu pioneirismo. Gêneros alimentícios de primeira necessidade eram vendidos a baixo custo, sendo descontados nas folhas de pagamentos dos funcionários. Em 1893, através da Socialidade de Mutualidade, a indústria pagava pensões aos empregados invalidados com mais de 25 anos de serviço.

Visando à formação intelectual e o lazer de sua mão de obra, oferecia um espaço com jornais e livros para a leitura, havendo nessa mesma edificação uma mesa de bilhar.

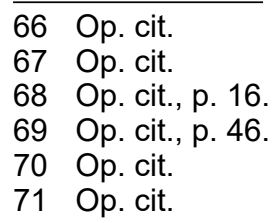

71 Op. cit. 
Posteriormente, em 1903, criou-se o Amparo Mútuo, com o intuito de pagar quotas às famílias em casos de falecimento do "chefe de família". As(os) trabalhadoras(es) tinham acesso a assistência médica e pecuniária por baixo custo, sendo também descontado das suas folhas de pagamento, no caso da utilização do serviço.

Dando continuidade a essas experiências anteriores, a Fábrica Renner de Porto Alegre (RS) trouxe uma série de inovações à promoção empresarial de políticas assistencialistas destinadas à classe trabalhadora. De acordo com Fortes, ${ }^{72}$ a experimentação de ações sociais defendidas pelos empresários da indústria Renner demonstra o papel de vanguarda na liderança de sua classe. Diante de discursos de "capitalismo social", visava-se a uma alternativa à "utopia comunista" e/ou o "estatismo".

Durante o período de funcionamento da Fábrica Rheingantz, de 1873 a 1968, três gerações de descendentes Rheingantz administraram a empresa. As três gerações buscaram estar presentes no chão da fábrica. Como menciona Oscar Rheingantz sobre o contato dos acionistas com os trabalhadores:

\begin{abstract}
Eu tenho uma norma de conduta. Sobre princípio que é base fundamental, que é verdade e é justiça. Isso eu aprendi, sei lá, talvez lendo Karl [Marx], lendo livros de Karl... Eu estive muito doente com 13 anos de idade, então eu estive muito tempo na cama. E nesse tempo eu li muito, li, li, li, li todos os livros de Karl, que era na época um escritor alemão e hoje está traduzido para o português. É um homem que, não é? Coisa interessante. Não sei por que eu tinha essa base de ser, de exigir a verdade e ser justo. (...). Todo chefe que é verdadeiro... e que é justo, ele adquire uma força moral, uma autoridade moral muito grande. $E$ isso eu... trans... continuei fazendo... O Jacques poderá saber melhor do que eu, porque ele é que ouvia as coisas, mas eu tenho a impressão de que ele não deve ter ouvido nunca uma queixa de um operário sobre mim. Porque eu nunca deixei de ouvir um empregado e nunca deixei de ah... de responder a ele... em termos... de justiça e verdade. ${ }^{73}$
\end{abstract}

Quando Oscar Rheingantz narra sobre Karl Marx, precisamos levar em conta que a entrevista oral é produzida a partir de uma relação entre entrevistado e entrevistador, na qual o entrevistado muitas vezes fala o que pensa que o entrevistador gostaria de ouvir. ${ }^{74}$ Porém, esse trecho da entrevista nos possibilita compreender as maneiras com as quais os empresários recorreram para fixar a mão de obra na empresa e apaziguar os conflitos gerados pelas condições de trabalho. Como Rezende aponta, "Além do objetivo de evitar conflitos, muitas práticas paternalistas visavam a estimular os trabalhadores a atingirem as metas de produção, realizar horas extras e executar tarefas distintas". ${ }^{75}$

A fala de Oscar Rheingantz marca a hierarquia na relação entre empregado e o empregador, "o chefe", porém, busca apaziguar os conflitos em uma narrativa que o enfatiza enquanto justo e verdadeiro com as(os) trabalhadoras(es). Como o empresário comenta, ele

72 Op. cit.

73 RHEINGANTZ, Oscar. Depoimento concedido em 1982. Rio Grande: Acervo Fábrica Rheingantz, Centro de Documentação Histórica Professor Hugo Alberto Pereira Neves, Fundação Universidade do Rio Grande, p. 29.

74 PORTELLI, Alessandro. O que faz a história oral diferente. Projeto história, v. 14, p. 25-39, 1997.

75 Op. cit., p. 229. 
sempre buscou responder ao operariado nos termos de justiça e verdade (os quais ele julgava ter). Logo, não haveria de ter queixa do operariado sobre ele.

Como ressalta Perrot ${ }^{76}$ é necessário que a mão de obra fabril reivindique e internalize as relações paternalistas, o que podemos verificar na fala de Soeli Botelho: "Ah é, eu não tenho nenhuma queixa dele. Era muito humano. Ele pode ter os erros dele, agora como humano ele erra". ${ }^{77}$ Soeli comenta sobre um episódio em que pediu um empréstimo financeiro a João Rheingantz:

Era o João Rheingantz. Porque eu trabalhava nos tapetes mesmo. Teve uma época que não dava para nada. Eu ajudava em casa. Meus dentes estavam estragando e eu ganhava pouco, não é? Aí eu fui lá em cima falar com o doutor João. Aí eu fui e disse assim para a Alva, essa que era contramestre dos tapetes, que era encarregada. E eu disse assim, - "Alva, eu vou lá em cima falar com o doutor João para ele me emprestar dinheiro para eu arrumar os dentes. Vou mentir para ele que estou doente". A Alva foi e disse assim: - "Não, Soeli. Tu vais lá e fala a verdade para ele, que ele é uma pessoa que tu estás conversando e ele está te olhando nos olhos. Ele sabe quando tu estás mentindo ou quando tu não estás. Tu falas para ele a verdade, que se ele tiver, ele vai te emprestar o dinheiro". Aí eu cheguei lá em cima e falei para ele que precisava de trezentos mil réis para arrumar meus dentes, que eu já não podia, que estava um caco. Se ele me emprestava os trezentos mil réis. Descontava, não é? Dez cruzeiros... dez mil réis por mês. Ele foi e disse assim: - Olha, a senhora volta aqui outro dia. Ele marcou a data pra eu ir lá e aí ele me emprestou os mil réis. E eu comecei a pagar naquela época 6 mil réis por mês. ${ }^{78}$

Rezende ${ }^{79}$ ao analisar o complexo industrial de Franca (SP), também constatou a concessão de "benefícios" pontuais dos empresários para as(os) trabalhadoras(es). Nas entrevistas analisadas por Rezende, as(os) trabalhadoras(es) relataram que os empresários de Franca faziam empréstimos financeiros antes da ordem de pagamento. Fontes, ${ }^{80}$ ao analisar a fábrica Nitro-Química de São Paulo, nos anos 1950, constata que a empresa cedia empréstimos às(aos) operárias(os) que pretendiam construir suas casas, com a finalidade de que elas/eles pudessem comprar materiais de construção. Além disso, os empresários da Nitro-Química distribuíam caixas de leite para suas/seus funcionárias(os), e o término dessa prática constituiu-se na memória da mão de obra relacionado à falência, a perda da grandeza que um dia a fábrica representou para o município e o país.

Speranza, ${ }^{81}$ analisando os mineiros do Rio Grande do Sul, entre os anos de 1940 e 1950, comenta a prática paternalista na fábrica-vila de São Jerônimo. Os empresários das minas montaram uma rede de assistência e lazer ao operariado, com hospital, clube

76 PERROT, Michelle. Os excluídos da história. Rio de Janeiro: Paz e Terra, 1988.

77 Op. cit., p. 11.

78 BOTELHO, op. cit., p. 27.

79 Op. cit.

80 FONTES, Paulo Roberto. Trabalhadores da Nitro-Química: a fábrica e as lutas operárias nos anos 50. Dissertação (Mestrado em História) - Instituto de Filosofia e Ciências Humanas, Universidade Estadual de Campinas, Campinas, 1999.

81 SPERANZA, Clarice Gontarski. Masculinidade, conflito e adesão: tensões identitárias entre os trabalhadores das minas de carvão do Rio Grande do Sul nos anos 1940. Artcultura, Uberlândia, v. 11, n. 18, p. 75-88, 2009. 
e cinema. Essa prática, segundo a autora, foi uma forma de atração e manutenção da mão de obra, assim como uma forma de legitimar a superexploração à qual essas(es) trabalhadoras(es) estavam submetidas(os).

Todavia, não eram os acionistas que supervisionavam cotidianamente a produtividade das(os) trabalhadoras(es). Como Rezende ${ }^{82}$ discute, ao passo que as fábricas se expandem e, consequentemente, seu corpo de funcionárias(os) aumenta, torna-se impossível que apenas os empresários supervisionem e tenham contato diário e cotidiano com a mão de obra da empresa. Como já exposto anteriormente, na Fábrica Rheingantz, os mestres, os contramestres e os encarregados cumpriam o papel de supervisionar o trabalho das(os) operárias(os). Nas entrevistas podemos identificar a presença de uma relação paternalista. Como comenta Soeli sobre sua relação com o mestre da seção de tapetes:

(...) Eu entrei em setembro de 1947, mesmo. Ele me chamou na mesa, chamou na mesa, ele me chamava de Soeli. Ele disse assim: "Soeli, vem para cá que eu quero falar contigo". Ele era muito reservado. E foi e disse assim para mim: "Toma, este envelope é para ti". Era um envelope via aérea. Ele foi e disse: "Guarda, não mostra para ninguém. Só abre na tua casa". Aí eu cheguei em casa e abri o envelope, agarrei e entreguei para mãe e disse: "Mãe, olha o que o mestre me deu". Abri o envelope e dentro do envelope tinha cinquenta cruzeiros. Aí eu fui e a mãe disse: "Mas por que ele te deu esse dinheiro?". Eu não sei. Aí no outro dia eu fui perguntar para ele o porquê que ele me deu aquele dinheiro. Ele foi e me disse assim: "Soeli, tu és uma menina pobre, uma menina que precisa. Tu mereces e não vais não... Tu precisas desse dinheiro, então, eu te dou de natal esses quinhentos cruzeiros para ti. Mas não diz para ninguém". Quando foi o segundo ano, começou aquele comentário, "vão dar o décimo terceiro, vão dar o décimo terceiro", que para a menor era cem cruzeiros e para maior era duzentos cruzeiros. Quando chegou o segundo ano na Rheingantz começaram a pagar o décimo terceiro. Era uma gratificação. Não era décimo terceiro, era gratificação da firma. Então, eram cem cruzeiros para menor e duzentos cruzeiros para maior. Aí começaram aqueles comentários: "vão pagar", "não vão pagar". E aí ele me chamou na mesa e foi e me deu o envelope e me disse assim para mim: "Toma, Soeli. Não vão pagar a gratificação. É pra ti”. Mas nunca ninguém ficou sabendo disso porque ele não queria que eu dissesse para ninguém. Para não haver comentário dentro da seção, mesmo. Aí eu cheguei em casa e tinha cem cruzeiros dentro do envelope. Mas aí eles pagaram os cem cruzeiros de gratificação. Aí eu cheguei nos tapetes e disse para ele: "Olha mestre, eu vim lhe dar os cem cruzeiros, porque o senhor disse que eles não iam pagar, mas eles pagaram. Então eu vim lhe dar os cem cruzeiros". E aquela época, é cem mil réis, não era... ${ }^{83}$

Essas práticas contribuíam para fomentar a noção de que todos os membros da empresa formavam uma grande família, discurso que fez parte do imaginário de outras empresas do Brasil, como as fábricas estudadas por Fontes ${ }^{84}$ e Rezende. ${ }^{85}$ Ao serem todos integrantes de uma única família, afasta-se a concepção de classes sociais distintas e com antagonismos.

82 Op. cit.

83 SOELI, op. cit., p. 26.

84 Op. cit.

85 Op. cit. 
Procurava-se neutralizar os movimentos políticos dos operários, se relacionando de maneira individualizada. ${ }^{86}$

Áureo Nunes de Almeida comenta o que mais o marcou no período em que trabalhou na Fábrica Rheingantz:

Ah, o espírito, o espírito. Nos primeiros tempos me marcou muito. Ah, o clima de familiaridade. Amizades que se criavam lá dentro. (...) Muito. Eu fui muito, muito, vamos dizer assim, ajudado. Amparado em fases da minha vida. Ah, mesmo a minha questão de saúde. Eu vou até citar o que aconteceu no caso da minha "bronquiectasia". O seu Paulo, como era chamado, ele me chamou no escritório e disse que eu queria, que eu precisava ser.... ah, entrar no lugar do desenhista técnico, o Hermelino, não é? Depois que eu já estava trabalhando uns meses com ele lá, como office boy. Tanto que imediatamente me tiraram da tinturaria. Depois então ele fez uma proposta para eu ser desenhista técnico. Até aí tem um acontecimento engraçado, ele disse para mim: - "O senhor vai para o lugar do Hermelino que está fazendo tratamento em Porto Alegre. Para ser desenhista técnico". Eu disse: - "Ah, mas seu Paulo, eu não sei desenhar". E ele disse: - "Não senhor, todos os seus irmãos são conhecidos como desenhistas. O senhor também tem que ser desenhista. (...) Não, não, o senhor está se subestimando, porque eu vi um trabalho seu na mão da Ana Maria". Ana Maria era uma sobrinha dele, mãe do Oscar Paulo Pernigotti, era casada com o seu Pernigotti. E esse era meu colega de ginásio, muito meu amigo, eu sempre ia veranear na casa deles no Bolacha. ${ }^{87}$

Áureo era filho de um trabalhador que permaneceu na Fábrica Reingantz por 52 anos e ocupou tarefas importantes lá. Segundo Áureo, ${ }^{88}$ seu pai trabalhou dezenas de anos à frente do setor de Mutualidade, responsável por promover políticas sociais voltadas ao operariado. As narrativas indicam que o contato direto entre empresários e funcionários ocorria apenas em cargos de maior especialidade e status. As funcionárias que ocupavam cargos de menor prestígio social, como Soeli Botelho ${ }^{89}$ e Margarida Soares Reis, ${ }^{90}$ retratam que havia uma distância entre elas e os industriais, em caracterizações que os definiam como "Muito quieto. Muito reservado". Assim, no caso das operárias, a relação individualizada se dava com o mestre e contramestre de suas seções.

A entrevista de Áureo indica que ele teve maiores oportunidades em progredir na empresa por já ser filho de um trabalhador que ocupava um cargo qualificado. Ainda na $4^{a}$ série, em 1943, o entrevistado fora convidado para trabalhar na empresa enquanto copiador de receitas. Ao ficar doente, ocupou o cargo de "office boy" e, alguns meses depois, ocupou o cargo de desenhista técnico da empresa, mesmo sem possuir formação anterior. Áureo residia na vila operária e tinha contato com a família Rheingantz, em uma relação direta com os empresários. Esse histórico parece ter influenciado a sua vivência na fábrica.

86 RAGO, Margareth, 2014.

87 Op. cit., p. 4.

88 Op. cit.

89 Op. cit.

90 Op. cit. 
Todavia, o paternalismo entra em choque com as condições de trabalho no chão da fábrica, o que também compõe a memória das(os) trabalhadoras(es). A narrativa de Margarida nos ajuda a compreender as condições de trabalho na empresa Rheingantz:

Tinha sim, pouco cuidado tinham. (...) Na minha seção, eu me lembro de um... eu me lembro de uma batida de tapete, não é? Eu fui virar o tear ao contrário e o tear voltou e me deu aqui. Quando me deu aqui assim... fiquei com o pé quebrado. Até hoje sinto, sentindo. Até o dedo aleijado e ficou uma mancha roxa. Fiquei 20 dias no seguro. Pensei até que tinha quebrado tudo. Que Deus me perdoe, que me dói até hoje. Toca aqui. Tantos anos... (...) Valia, pagavam muito (indenizações por acidentes). E tinha também muitas coisas que aconteciam lá dentro. Também, não é? Os que escorregavam, caíam, se pisavam. Para ver se quebravam uma perna... (pausa). Puxava o tapete e escorregava... tapete também...91

Na seção na qual os episódios narrados por Margarida de Souza Reis aconteceram, o trabalho era desempenhado por trabalhadoras menores de idade. Quando perguntada se o trabalho na seção dos tapetes era "mais fácil", Soeli Botelho respondeu com negação:

Serviço muito puxado. Quer dizer, os martelos são tudo de ferro e os teares são abertos à mão. Fechar os teares e abrir os teares à mão. Bater os tapetes com o martelo de ferro, passar a lançadeira à mão. Porque o tapete é todo feito à mão. E os salários eles pagavam e pagam ainda um salário mínimo. ${ }^{92}$

Ao falar dos acidentes no local de trabalho, Margarida Soares Reis relatou, em 1987, que a Fábrica Rheingantz disponibilizava para seus funcionários indenização e atendimento médico, demonstrando que, além dos discursos paternalistas, os benefícios sociais cedidos pela empresa também corroboraram para apaziguar as contradições sociais no chão da fábrica. Rezende $^{93}$ intitulou essa prática como "capitalismo de bem-estar social".

Esse é o caso da Fábrica Rheingantz, que desde sua fundação se destacou pela sua estrutura e capital investido. Sobre a assistência médica e acidente no trabalho, Margarida Souza Reis comentou: "Tinha toda assistência, até hospital. Tinha todinha. Tinha hospital e toda assistência médica por conta deles. Era muito boa a fábrica. Agora não é mais a Rheingantz, não é?". ${ }^{44} \mathrm{Na}$ época da entrevista, a empresa havia passado por transformações estruturais, visto que, a partir de 1970, ela pertencia a outro grupo de acionistas, não mais da família fundadora, passando a se intitular Inca Têxtil.

Ao lembrarem do período em que a família Rheingantz administrava a empresa, as(os) operárias(os) relacionam o auge da fábrica com os benefícios sociais e as premiações financeiras concedidos. Dario Camposilvan ressalta que esses benefícios antecederam as leis de trabalho, criadas no governo de Getúlio Vargas:

Próprio da firma. Sim, porque a firma, em relação a... No caso das leis sociais, ela começou a manter essas leis, a partir de [19]35 ou antes?? Sim, porque

91 REIS, op. cit., p. 6-7.

92 Op. cit., p. 3.

93 Op. cit.

94 Op. cit., p. 5 
a partir de [19]35 todos funcionários já tinham essas leis. Já tinham essas contribuições. ${ }^{95}$

O empresário Carlos Guilherme Rheingantz ${ }^{96}$ é visto como um homem à frente de seu tempo, um indivíduo que foi pioneiro na criação de benefícios sociais às(aos) operárias(os) e influenciou outras empresas a adotarem essa política. Dario Camposilvan comenta: "Abriu campo para o bem-estar social, favorecendo mais a comunidade "fabrilista" e servindo de modelo para que 13 outras firmas o copiassem" (CAMPOSILVAN, 1981, p. 2). Oscar Rheingantz é enfático ao se referir ao seu avô:

O meu avô é... com esse estudo da Alemanha, no tempo do Bismarck, ele trouxe para cá essa preocupação pelo operário, pelo cidadão comum, pelo homem comum, pelo pobre, certo? É, então, ele veio preocupado com a moradia, com a saúde e com a alimentação, certo? Aliás, com a educação. E acabou preocupado com a alimentação de falta de legumes, pão. Então andou se preocupando com trigo e outros. Bom, é... ele então, quando ele veio em... quando ele fundou a fábrica em 1873, já em 1880 ele começou a construir as casas para os operários. ${ }^{97}$

Fontes $^{98}$ aponta que o discurso de fábrica "família" e a política social redefiniram os laços afetivos e sociabilidade das(os) trabalhadoras(es). Havia a predominância de migrantes nordestinos trabalhando na empresa Nitro-Química (SP), sujeitos esses que muitas vezes vinham sozinhos, sem as suas famílias. Esse fenômeno possibilitou o êxito do paternalismo, na interiorização desses discursos pelas(os) trabalhadoras(es). Pensando no contexto da Fábrica Rheingantz, grande parte de sua mão de obra era imigrante ou migrante, então, no próprio chão da fábrica, as identidades coletivas, muitas vezes, se redefiniam. Sendo assim, há a possibilidade de que a diversidade de sujeitos que integravam a mão de obra pudesse contribuir ao êxito das práticas paternalistas averiguadas nas narrativas das(os) trabalhadoras(es) da Rheingantz.

As comemorações festivas e as realizações de festas e jogos de futebol na vila operária foram condutas recorrentes no período de funcionamento da fábrica. Nessas comemorações festivas se encontravam as(os) trabalhadoras(es) e os donos da Rheingantz, intensificando o simbolismo de família fabril. Além disso, as horas de lazeres e sociabilidade eram importantes para que as(os) trabalhadoras(es) abstraíssem as condições de trabalho e as contradições do chão da fábrica, sendo, também, uma interferência direta da empresa na vida privada de seu operariado. ${ }^{99}$

Como comenta Dario Camposilvan, quando perguntado sobre o Clube União Fabril:

Não, a Companhia Ihe emprestava o nome. Seu quadro social compunha-se única e exclusivamente de empregados e funcionários da empresa. (...) Os funcionários, certo? Em jogos e festas de cunho social. Futebol de campo,

95 Op. cit., p. 18.

96 Nascido em 14 de abril de 1849, Carlos Guilherme Rheingantz funda, aos 25 anos de idade, a Fábrica Rheingantz, após a morte de seu pai Jacob Rheingantz, de origem alemã e fundador da colônia de São Lourenço do Sul, no Rio Grande do Sul.

97 Op. cit., p. 12.

98 Op. cit.

99 REZENDE, op. cit. 
bolão e mais tarde de futebol de salão. Baile, espetáculos e outros atrativos. (...) Ele pagava mensalidade. (...) Era descontado em folha. Os filhos dos funcionários não pagavam. ${ }^{100}$

Eram recorrentes as comemorações quando o(a) trabalhador(a) completava significativos anos de casa, nas quais as(os) trabalhadoras(es) recebiam homenagens e premiações. Interpreto que essa prática tinha a pretensão de elevar o moral da mão de obra, que se sentiria valorizada pelos serviços prestados à empresa. Ações essas que também estão presentes nas indústrias estudadas por Fontes ${ }^{101}$ e Rezende, ${ }^{102}$ como comenta Botelho:

Baile social, por exemplo, entregava diploma quando a gente fazia... por exemplo, 25 anos de casa. (...) Ah, tinha os prêmios. Vinte e cinco anos ganhava um diploma. Inclusive, uma vizinha minha tem um diploma. (...) Vinte cinco anos. (...). Bodas de prata. (...) Ah, eram. Eram divertidos, mesmo. (...) Prêmio extra, assim, um dinheiro " $x$ ". (...) Não, de acordo com o que o funcionário fazia, não é? Se o funcionário fazia muito. Muito como é... tinha muita produção, tinha um prêmio. (...) É, é, é, era valorizado. ${ }^{103}$

Percebe-se a partir da análise desenvolvida até aqui que as punições, os benefícios sociais e o discurso paternalista percorreram as vivências das(os) trabalhadoras(es) e acionistas da Fábrica Rheingantz. As fontes e a literatura acerca de vilas operárias apontam que essa foi uma prática recorrente durante o século $X X$ e possuía a finalidade de fixar a mão de obra nas indústrias, diminuindo os conflitos de classe. A interferência direta da empresa no cotidiano dos trabalhadores ampliava as formas de dominação de classe, fazendo com que as memórias do operariado acerca da fábrica fossem constituídas por saudosismo, e a imagem dos acionistas fosse de pessoas humanitárias e benfeitoras.

\section{Considerações finais}

CONSTATOU-SE que a promoção de políticas assistencialistas na Fábrica Rheingantz visava à fomentação do sentimento de harmonia social na empresa, buscando diminuir as tensões de classe existentes no chão da empresa. As(os) entrevistadas(os) recordam do tempo de funcionamento da Fábrica Rheingantz com saudosismo, os proprietários da indústria são vistos pelas(os) trabalhadoras(es) como benfeitores, pessoas à frente do seu tempo. Todavia, percebe-se, também, que a política de concessão de moradias promoveu memórias conflitantes nas entrevistadas, apontando o limite da fomentação da harmonia social nas práticas paternalistas da Fábrica Rheingantz.

Aponta-se que o trabalho reprodutivo e de cuidado esteve presente como uma problemática dos empresários Rheingantz, que buscaram garantir a reprodução do seu operariado a partir de criação de políticas assistencialistas voltadas para a reprodução.

100 Op. cit., p. 4.

101 Op. cit.

102 Op. cit.

103 BOTELHO, op. cit., p. 38. 
Percebemos que a unidade familiar, a esfera privada, são importantes aspectos a serem analisados em pesquisas sobre fábricas e vilas operárias. Ressalta-se, em consonância com os estudos de gênero, que devemos ampliar o nosso entendimento sobre o que é trabalho, promovendo análises acerca da considerável massa de trabalho desempenhada gratuitamente pelo sexo feminino.

Recebido em 26/04/2021

Aprovado em 03/08/2021 